use of the blank, are obtained by redissolving the magnesium pyrophosphate and reprecipitating.

5. That five minutes digestion at $65^{\circ} \mathrm{C}$. seems to be sufficient for the complete precipitation of phosphoric acid by molybdic solution.

AgRICLltural EXPERIMENT STation,

MORGantown, WRSt VIRGINia,

November I2, 5894 .

\title{
THE ADDITION OF CALCIUM CHLORIDE TO THE SOLU- TION OF A FERTILIZER IN THE DETERMINATION OF POTASH.
}

BY RUDOLF DE ROODE.

Received November 26,1894

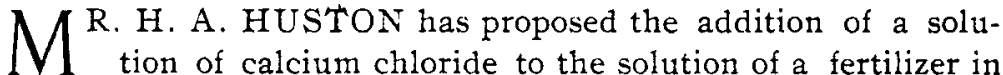
the determination of potash, in order to furnish sufficient calcium to form tricalcium phosphate with all the phosphoric acid present, and thereby permit of the use of platinim dishes in the Lindo-Gladding method. In testing this proposition $I$ find that when sufficient calcium chloride was added to combine with all the phosphoric acid present and then ammonia added in excess and a portion of the solution filtered off, no test for phosphoric acid could be obtained. But, that if in addition to the calcium chloride and ammonia, some ammonium oxalate or carbonate was added, a filtered portion of the solution did give a test for phosphoric acid. This is accounted for by the fact that the calcium phosphate, which was precipitated by the ammonia, is changed by the ammonium oxalate or carbonate into calcium oxalate or carbonate and ammonium phosphate, so that the very object for which the calcium chloride was added is defeated by the addition of the ammonium oxalate or carbonate In order to make the use of calcium chloride effective it is necessary to filter off from the precipitate formed by the calcium chloride and ammonia and to then add the ammonium oxalate or carbonate to the filtrate. This necessitates two separate filtrations, and it is doubtful if we have in Mr. Huston's suggestion anything better than, or even so good as in the present alternate method.

Agricultural Experiment Station,

Morgantown, West Virginia,

November Ia, I 894 . 